\title{
Evaluation of nineteen food wastes for essential and toxic elements
}

\author{
Saranya Kuppusamy ${ }^{1,2,3} \cdot$ Kadiyala Venkateswarlu $^{4} \cdot$ Mallavarapu Megharaj $^{2,3,5}$
}

Received: 11 April 2017/ Accepted: 4 October 2017/Published online: 9 October 2017

(C) The Author(s) 2017. This article is an open access publication

\begin{abstract}
Purpose The study evaluates and provides an overview of the nutritional importance of 19 selected food wastes as aids in human/livestock/soil/plant health.

Methods Nitric acid-digested extracts of food wastes belonging to four different classes (fruits, vegetables, oilseeds and beverages) were analysed for different elements in an inductively coupled plasma mass spectrometer.

Results Our study recommends spent coffee grounds, tea leaves, radish peel, watermelon rind and pineapple skin that contain substantially high concentrations of essential elements such as $\mathrm{N}, \mathrm{P}, \mathrm{K}, \mathrm{S}$ and $\mathrm{Fe}$ for their use as: (a) substrates for composting, (b) biofertilizers, (c) soil amendments, and (d) bioadsorbents of toxins. Although these food wastes are rich in essential nutrients, we do not suggest them for the preparation of food supplements as they contain non-essential elements in concentrations beyond the human safety limits. However, food wastes like banana peel, plum pomace and pistachio shell that contain
\end{abstract}

Saranya Kuppusamy

saran.miles2go@gmail.com

1 Institute of Agriculture and Life Science, Gyeongsang National University, Jinju 660-701, South Korea

2 Centre for Environmental Risk Assessment and Remediation (CERAR), University of South Australia, Mawson Lakes, SA 5095, Australia

3 Cooperative Research Centre for Contamination Assessment and Remediation of Environment (CRC CARE), PO Box 486, Salisbury South, SA 5106, Australia

4 Formerly Department of Microbiology, Sri Krishnadevaraya University, Anantapur 515055, India

5 Global Centre for Environmental Remediation (GCER), Faculty of Science and Information Technology, The University of Newcastle, Callaghan, NSW 2308, Australia low and permissible concentrations of toxic elements can be recommended as dietary supplements for oral intake in spite of their lesser essential elemental composition than the other residues examined.

Conclusions Our study confirms that food wastes are rich sources of essential nutrients and there is need to harness their real industrial systems.

Keywords Food wastes · Nutrients - Essential elements · Waste management

\section{Introduction}

Global food production is estimated to be 6273 million tonnes per annum, of which one-third (2375 million tonnes) is contributed by cereals followed by fruits and vegetables (1600 million tonnes). Around 60\% of the total food produced is lost or wasted so that the final household consumption accounts for only 2438 million tonnes per annum. This waste is an ample portion of the food that can feed the estimated 3 billion starving people in the world. Food losses are paramount in industrialized Asian and European countries in addition to South and Southeast Asia. Nearly $14 \%$ of the greenhouse gas emission is from the food waste (Gustavsson et al. 2011). As the accumulation of food wastes is detrimental to the environment, concerns are rising and there is a need to develop ecofriendly technologies for the minimization of food wastes. In addition, according to an UN estimate, by 2050 the mass of global food waste will increase even further as food production is expected to increase by 70\% (FAO 2013). Hence, governments as well as international organizations are currently focusing more on waste management issues. In recent days, efforts have been made to transform food 
wastes into products of commercial utility as they are very rich in bioactive compounds such as vitamins, minerals, amino acids and polyphenols. Among these bioactive compounds, some essential mineral elements play an important role as cofactors in many enzymatic processes involved in humans, plants, animals and soil microbes (Kuppusamy et al. 2015).

Industries and households are the major sources of food wastes. Detailed studies of the food wastes originating from these two sources, especially from households, are meagre. With this in mind, the study reported here mainly focused on household food wastes along with some common industrial wastes such as pomace and pulp from agricultural by-products. Fruits, vegetables, oilseeds and beverages are the commodity groups that contribute to the major share of the food wastes. These four classes of food wastes were considered for evaluation in the present study as they contribute particularly large quantities of essential elements. Apart from essential elements, food wastes are expected to contain traces of toxic elements which may or may not be within human health or environmental permissible limits. Information on the detailed toxicological profile of the most common food wastes such as butternut peel, onion peel, watermelon rind, radish peel, pineapple skin, strawberry pomace, plum pomace and pistachio shell is so far not reported in the literature. The available literature shows only the utilization of food wastes, but not their full elemental composition. Since such information would facilitate their effective utilization, the primary objective of our study was to evaluate and provide an overview of the nutritional importance of 19 selected food wastes as aids in human/livestock/soil/plant health.

\section{Materials and methods}

\section{Samples of food wastes}

The food materials investigated were the wastes of 19 types of fruits, vegetables, oilseeds and beverages procured from local markets in South Australia. Five copies of each waste collected from same market have been analysed. Orange (Citrus sinensis (L.) Osbeck), watermelon (Citrullus lanatus (Thunb.) var. lanatus), honeydew (Cucumis melo L.), banana (Musa paradisiaca L.), butternut (Cucurbita moschate Duchesne ex Poir.), pineapple (Ananas comosus (L.) Merr.), potato (Solanum tuberosum L.), onion (Allium cepa L.), radish (Raphanus sativus subsp. sativus (L.) Domin), pistachio (Pistacia vera L.) and peanut (Arachis hypogaea L.) samples were cleaned, manually peeled, and the peels/rinds/skin/shell cut into small pieces and dried in a temperature-controlled room $\left(37^{\circ} \mathrm{C}\right)$ for 2 weeks. Subsequently, apple (Malus domestica Borkh.), strawberry
(Fragaria ananassa Duchesne), plum (Prunus domestica L.), grape (Vitis vinifera L.), carrot (Daucus carota L.), and olive (Olea europaea L.) were grated, homogenised and filtered for separating the juice. The pomace or pulp left after juice extraction was dried in a forced air oven at $40{ }^{\circ} \mathrm{C}$ for $72 \mathrm{~h}$. Similarly, spent coffee grounds (Coffea arabica L.) and tea (Camellia sinensis (L.) Kuntze) leaves were also dried. After complete drying, the samples were finely ground to a particle size of approximately $0.5 \mathrm{~mm}$ with a coffee grinder and were stocked in sealable polythene bags in a desiccator until further use.

\section{Digestion and analysis for total metals}

Elemental composition (except $\mathrm{C}$ and $\mathrm{N}$ ) of the selected food wastes was analysed in digests after sample decomposition in nitric acid. About $0.5 \mathrm{~g}$ of the sample was digested with $5 \mathrm{~mL}$ of $70 \%$ conc. $\mathrm{HNO}_{3}$ in a Teflon digestion vessel using a microwave accelerated reaction system (CEM-MARS $\mathrm{X}^{\circledR}$ ) according to US EPA method 3015a. After digestion, the residue was diluted with $50 \mathrm{~mL}$ of the deionized water and filtered through $0.45 \mu \mathrm{m}$ filter. A $10 \mathrm{~mL}$ diluted aliquot was analysed for different elements in an Agilent 7500c (Agilent Technologies, Tokyo, Japan) inductively coupled plasma mass spectrometer (ICP-MS) using a modified method described by Das et al. (2002). Another $0.5 \mathrm{~g}$ of the dry ground sample was used for total C and $\mathrm{N}$ analysis using a Trumac (Leco ${ }^{\circledR}$ Corporation, Michigan, USA) Carbon-Nitrogen-Sulphur analyser (CNS analyser). All samples were assayed in triplicate, and the data are expressed on dry weight of the samples.

\section{Statistical analysis}

All experimental data are presented as mean values of three observations with their corresponding standard deviations. Differences between means were tested for significance by one-way ANOVA with Tukey's test using SPSS (Statistical Program for Social Sciences, IBM ${ }^{\circledR}$ Corporation, USA) statistical software v.20. Differences at the $P<0.05$ were considered to be significant.

\section{Results and discussion}

Figure 1 and Table 1 shows the results of chemical analyses of the macroelements present in the selected food wastes. Of the 19 food wastes considered, beverage wastes stood out clearly from the others for their high macroelemental content (554-556 $\mathrm{mg} \mathrm{g}^{-1}$ dry wt.) followed by oilseeds (473-519 $\mathrm{mg} \mathrm{g}^{-1}$ ) and fruits (428-516 $\mathrm{mg} \mathrm{g}^{-1}$ ) (Fig. 1). Vegetable wastes had the lowest values ranging from 438 to $488 \mathrm{mg} \mathrm{g}^{-1}$ sample. Spent coffee grounds and 
Fig. 1 Concentration of total macroelements (dry weight basis) in different food wastes

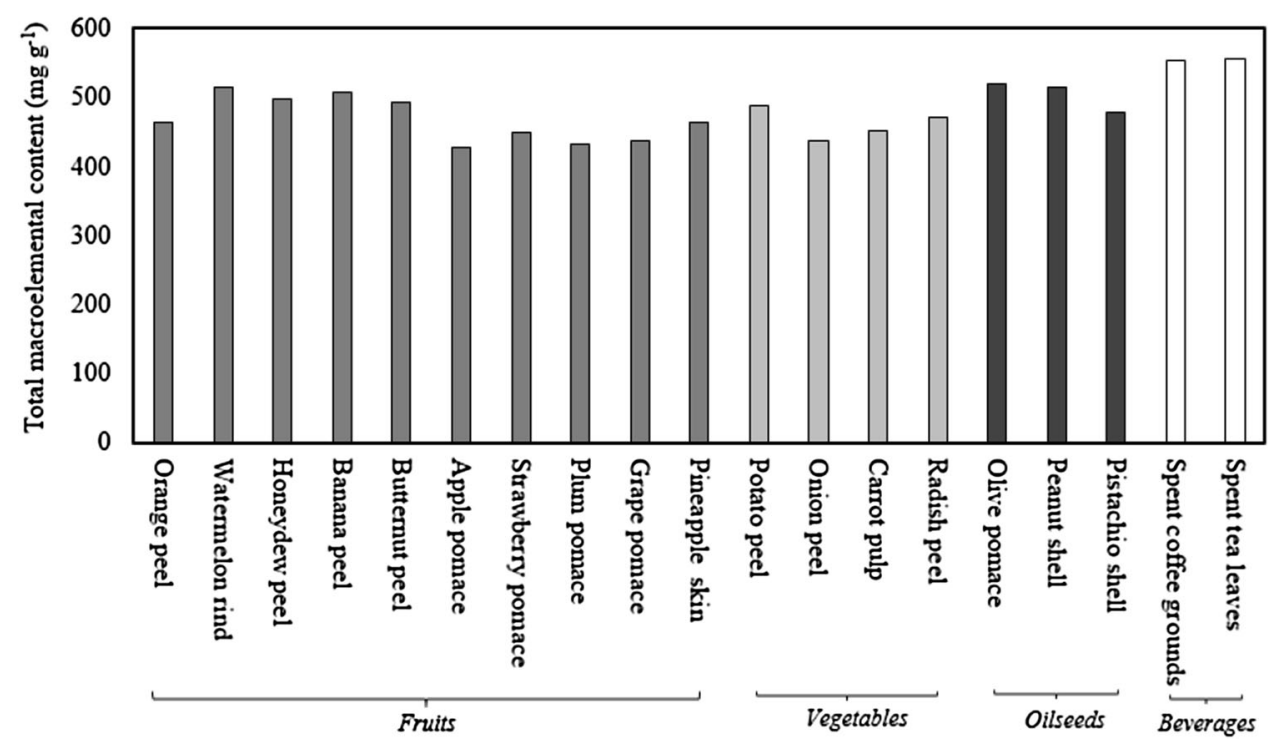

Table 1 Concentrations ( $\mathrm{mg} \mathrm{g}^{-1}$ dry weight) of macroelements in different food wastes

\begin{tabular}{|c|c|c|c|c|c|c|c|c|}
\hline \multirow[t]{2}{*}{ Food class and waste } & \multicolumn{4}{|c|}{ Primary macroelements } & \multicolumn{4}{|c|}{ Secondary macroelements } \\
\hline & $\mathrm{C}$ & $\mathrm{N}$ & $\mathrm{P}$ & $\mathrm{K}$ & $\mathrm{Ca}$ & $\mathrm{Mg}$ & $\mathrm{S}$ & $\mathrm{Na}$ \\
\hline \multicolumn{9}{|l|}{ a. Fruits } \\
\hline Orange peel & $433.7 \pm 32$ & $8.5 \pm 1.2$ & $1.1 \pm 1.5$ & $10.2 \pm 3.8$ & $8.5 \pm 2.1$ & $0.7 \pm 2.2$ & $0.5 \pm 1.6$ & $0.7 \pm 4$ \\
\hline Watermelon rind & $373.4 \pm 12$ & $42.2 \pm 2.6$ & $10.7 \pm 1.0$ & $73.4 \pm 1.5$ & $6.3 \pm 2.4$ & $3.8 \pm 2.7$ & $4.5 \pm 1.3$ & $1.6 \pm 2.8$ \\
\hline Honeydew peel & $430.5 \pm 11$ & $16.0 \pm 1.5$ & $4.8 \pm 1.1$ & $37.0 \pm 1.6$ & $1.8 \pm 1.6$ & $3.6 \pm 0.1$ & $1.8 \pm 1.7$ & $2.0 \pm 3.8$ \\
\hline Banana peel & $426.1 \pm 86$ & $9.9 \pm 1.8$ & $1.9 \pm 1.5$ & $65.2 \pm 4.2$ & $2.6 \pm 1.1$ & $1.5 \pm 0.1$ & $0.4 \pm 1.2$ & $0.05 \pm 3.2$ \\
\hline Butternut peel & $427.4 \pm 21$ & $27.7 \pm 2.3$ & $6.2 \pm 1.2$ & $24.7 \pm 3.2$ & $2.7 \pm 1.1$ & $3.1 \pm 0.5$ & $1.4 \pm 1.6$ & $0.01 \pm 3.6$ \\
\hline Apple pomace & $414.4 \pm 26$ & $4.1 \pm 1.5$ & $0.8 \pm 1.6$ & $8.2 \pm 4.1$ & $0.2 \pm 4.3$ & $0.3 \pm 2.4$ & $0.2 \pm 1.9$ & $0.04 \pm 5.8$ \\
\hline Strawberry pomace & $432.2 \pm 52$ & $2.9 \pm 1.6$ & $0.7 \pm 1.6$ & $7.5 \pm 1.1$ & $2.7 \pm 1.9$ & $1.2 \pm 2.9$ & $0.3 \pm 1.6$ & $0.8 \pm 1.4$ \\
\hline Plum pomace & $413.7 \pm 59$ & $3.7 \pm 1.1$ & $1.2 \pm 5.0$ & $11.5 \pm 1.4$ & $0.2 \pm 1.4$ & $0.4 \pm 2.9$ & $0.1 \pm 1.1$ & $0.6 \pm 2.6$ \\
\hline Grape pomace & $415.0 \pm 29$ & $5.9 \pm 0.8$ & $1.1 \pm 2.8$ & $13.3 \pm 1.9$ & $0.8 \pm 1.3$ & $0.5 \pm 4.6$ & $0.4 \pm 1.5$ & $0.02 \pm 2.2$ \\
\hline Pineapple skin & $446.2 \pm 31$ & $12.8 \pm 1.1$ & $0.1 \pm 1.4$ & $0.5 \pm 1.9$ & $2.2 \pm 1.9$ & $0.7 \pm 3.2$ & $0.6 \pm 1.1$ & $0.9 \pm 2.0$ \\
\hline \multicolumn{9}{|l|}{ b. Vegetables } \\
\hline Potato peel & $420.2 \pm 61$ & $22.2 \pm 1.3$ & $3.2 \pm 1.8$ & $34.8 \pm 1.2$ & $1.2 \pm 4.2$ & $1.2 \pm 1.9$ & $1.6 \pm 1.1$ & $3.6 \pm 1.2$ \\
\hline Onion peel & $410.2 \pm 59$ & $3.4 \pm 1.1$ & $0.2 \pm 1.6$ & $2.5 \pm 1.8$ & $12.9 \pm 1.2$ & $2.8 \pm 2.3$ & $0.9 \pm 1.2$ & $4.8 \pm 5.2$ \\
\hline Carrot pulp & $402.3 \pm 82$ & $10.0 \pm 2.3$ & $3.3 \pm 2.9$ & $23.4 \pm 1.1$ & $2.8 \pm 2.6$ & $1.3 \pm 2.2$ & $0.8 \pm 1.2$ & $9.0 \pm 1.1$ \\
\hline Radish peel & $367.4 \pm 22$ & $39.9 \pm 1.5$ & $6.9 \pm 1.6$ & $39.6 \pm 1.2$ & $5.5 \pm 1.2$ & $2.6 \pm 1.5$ & $6.9 \pm 1.1$ & $2.2 \pm 3.2$ \\
\hline \multicolumn{9}{|l|}{ c. Oilseeds } \\
\hline Olive pomace & $473.9 \pm 18$ & $11.2 \pm 2.0$ & $2.0 \pm 1.3$ & $28.6 \pm 2.1$ & $1.7 \pm 1.6$ & $0.9 \pm 1.6$ & $0.8 \pm 1.9$ & $0.3 \pm 1.6$ \\
\hline Peanut shell & $473.8 \pm 90$ & $6.8 \pm 1.3$ & $2.5 \pm 1.6$ & $26.7 \pm 1.6$ & $1.5 \pm 1.2$ & $0.8 \pm 1.9$ & $1.8 \pm 1.2$ & $0.3 \pm 1.3$ \\
\hline Pistachio shell & $467.1 \pm 32$ & $5.0 \pm 0.5$ & $0.05 \pm 1.8$ & $1.4 \pm 1.9$ & $0.3 \pm 1.5$ & $0.06 \pm 1.7$ & $0.09 \pm 1.2$ & $5.3 \pm 2.1$ \\
\hline \multicolumn{9}{|l|}{ d. Beverages } \\
\hline Spent coffee grounds & $524.1 \pm 41$ & $21.6 \pm 1.0$ & $0.7 \pm 1.9$ & $3.9 \pm 1.5$ & $1.1 \pm 1.9$ & $1.1 \pm 1.2$ & $0.8 \pm 1.0$ & $0.1 \pm 0.9$ \\
\hline Spent tea leaves & $494.8 \pm 21$ & $36.1 \pm 0.2$ & $2.6 \pm 1.1$ & $6.4 \pm 1.9$ & $11.6 \pm 1.3$ & $1.3 \pm 1.9$ & $1.8 \pm 2.1$ & $1.5 \pm 0.2$ \\
\hline
\end{tabular}

Values are mean \pm standard deviation $(n=3)$

onion peel, followed by watermelon rind were also observed to contain substantial levels of macronutrients and could be used as nutrient-rich feed additives for livestock or as dietary supplements for humans. The lowest concentrations of macroelements were detected in apple and plum pomace ( 428 and $431 \mathrm{mg} \mathrm{g}^{-1}$, respectively).

The order of elemental concentrations in the food wastes was $\mathrm{C}>\mathrm{K}>\mathrm{N}>\mathrm{Ca}>\mathrm{P}>\mathrm{Na}>\mathrm{Mg}>\mathrm{S} \quad$ (Table 1). 
Clearly, there exists a significant variability in the elemental composition of different food wastes tested. These substantial differences in the elemental composition of food wastes strongly account for their distinct beneficial activities when exploited. The highest levels of $\mathrm{C}$ were found in spent coffee grounds and tea leaves. Caetano et al. (2012) observed a similar C content for spent coffee grounds. These wastes can be used as substrates in fermentations, compost or biofertilizer preparations to stimulate the growth of microbes involved in those processes, as $\mathrm{C}$ is the most significant element that accelerates microbial activity and diversity.

Watermelon rind recorded the maximum NPK concentrations followed by radish peel. Both were also observed to be the rich sources of $\mathrm{Mg}$ and $\mathrm{S}$. These food wastes can be applied as soil amendments as they could possibly elevate limiting soil nutrients such as N, P, K and S. A dual role of increasing soil health by nutrient cycling as well as reducing the cost involved in the agricultural production by replacing the use of synthetic fertilizers with these natural wastes could be achieved. This could also be an economically sound waste management strategy. The highest $\mathrm{Ca}$ and $\mathrm{Na}$ concentrations were found in onion $\left(12.9 \pm 1.2 \mathrm{mg} \mathrm{g}^{-1}\right)$ and carrot $\left(9.0 \pm 1.1 \mathrm{mg} \mathrm{g}^{-1}\right)$ peel. Pistachio shell had low concentrations of $\mathrm{K}$ and $\mathrm{Mg}$. Further, the least $\mathrm{Ca}$ and $\mathrm{S}$ concentrations were found in apple and plum pomaces. The Ca content reported by Er and Ozcan (2010) for apple pomace was $31 \times$ higher than our observations made in the present analysis. A similar report with threefold higher $\mathrm{Ca}$ values was made by Joshi and Attri (2006). The variability in the elemental composition among the food wastes can be attributed to the different digestion methods, and also to dissimilar varieties and harvest season of the samples analysed by us, as these parameters affect the accumulation of the mineral elements in plant parts.

The data on concentrations for the essential trace and toxic elements in the selected fruit, vegetable, oilseed and beverage wastes are presented in Table 2 and Fig. 2. The trace elements in the food wastes decreased in the order: $\mathrm{Fe}>\mathrm{Mn}>\mathrm{Cu}>\mathrm{Zn}>\mathrm{Cr}>\mathrm{Ni}>\mathrm{Co}$. In general, the concentration of essential trace elements in the wastes ranged from 9 to $635,20-552,1-106$ and $60-632 \mathrm{mg} \mathrm{kg}^{-1}$ for fruit, vegetable, oil seed and beverage (Fig. 2a), respectively, and this trend are quite similar to that observed for the total macronutrient concentrations. Of the 19 food wastes considered, pineapple skin and spent tea leaves were shown to contain the highest amounts of essential trace elements, whereas pistachio shell and apple pomace had the least. Spent tea leaves are a rich source of most of the essential trace elements including $\mathrm{Mn}, \mathrm{Ni}$, and $\mathrm{Cr}\left(295 \pm 28,5 \pm 1.5\right.$, and $21 \pm 3 \mathrm{mg} \mathrm{kg}^{-1}$, respectively) (Table 2). One of the significant findings of our study is that the prime sources of $\mathrm{Fe}$ among the food wastes are pineapple skin and radish peel (with $13-67 \times$ higher values than the other food residues tested). Radish peel was also observed to be a rich source of $\mathrm{Cu}$ and $\mathrm{Co}(46 \pm 3.2$ and $0.5 \pm 1 \mathrm{mg} \mathrm{kg}^{-1}$, respectively). Er and Ozcan (2010) found somewhat different concentrations of essential trace element for the apple pomace than our present values. The only report available in the literature (Mussatto et al. 2011) for the essential trace element composition of spent coffee grounds is $20 \times$ lower than the data reported in our study.

In general, toxic/non-essential elements have no biological role and it is necessary to determine their levels before recommending as natural resources for utility. For this group of elements, most of the food wastes contained $\mathrm{Al}$ followed by $\mathrm{Pb}, \mathrm{Cd}$ and As. Pineapple skin tended to accumulate $\mathrm{Al}$ $\left(590 \pm \mathrm{mg} \mathrm{kg}^{-1}\right), \quad$ As $\left(0.2 \pm 0.1 \mathrm{mg} \mathrm{kg}^{-1}\right)$ and $\mathrm{Pb}$ $\left(6.4 \pm 2.1 \mathrm{mg} \mathrm{kg}^{-1}\right)$. The highest concentrations of As were also found in apple pomace $\left(0.2 \pm 0.1 \mathrm{mg} \mathrm{kg}^{-1}\right)$ (Table 2). Also, Cd was high in olive pomace $\left(2.9 \pm 1.6 \mathrm{mg} \mathrm{kg}^{-1}\right)$. The total toxic metal contents were high in pineapple skin $\left(597 \mathrm{mg} \mathrm{kg}^{-1}\right.$ ) followed by spent tea leaves $\left(568 \mathrm{mg} \mathrm{kg}^{-1}\right.$ ) (Fig. 2b). However, no traces of toxic metals were detected in pistachio shell, so it might be safe to use as an additive while preparing human/livestock feeds from this waste material. Reports are not available in the literature to compare the above data as toxicity of the food wastes has so far been unexplored in the detailed way as in our study.

It was observed that the toxic metal and metalloid concentrations were generally above the tolerable monthly intake levels for most of the food wastes (WHO 2015). These toxic elements might have come from the soil as the soils from where these food crops grew may have been polluted. Also, the results of the study reveal that the peels/ rinds/skin/pulp or pomace of food components tend to preferentially accumulate the toxic elements and it is thus a safer practice in our day-to-day life to discard them without consumption. However, their bioavailability depends on the acidity. When food wastes are formulated by following a certain process, by maintaining the alkalinity, the toxic elements can be rendered non-bioavailable. The ranges found in our study are high only with regard to the monthly intake level $\left(2 \mathrm{mg} \mathrm{kg}^{-1}\right.$ for $\mathrm{Al} ; 21 \mu \mathrm{g} \mathrm{kg}^{-1}$ for As and $\mathrm{Pb}$; $25 \mathrm{\mu} \mathrm{kg}^{-1}$ for Cd) (WHO 2015), and are not barred from consumption. Hence, one can formulate dietary supplements or nutritive additives combining two or more wastes so that their toxic elemental level is kept below regulatory health limits. It is noteworthy that banana peel, plum pomace and pistachio shell had toxic elemental concentrations below the human intake limits. Therefore, these three wastes are perceived to be ecologically safe for human/livestock utility. On the other hand, the concentration of toxic metals and metalloids ( $\mathrm{As}, \mathrm{Cd}$ and $\mathrm{Pb}$ ) were below the environmental safety limits (NEPM 2011). The ubiquitous element, $\mathrm{Al}$, which was detected at higher 


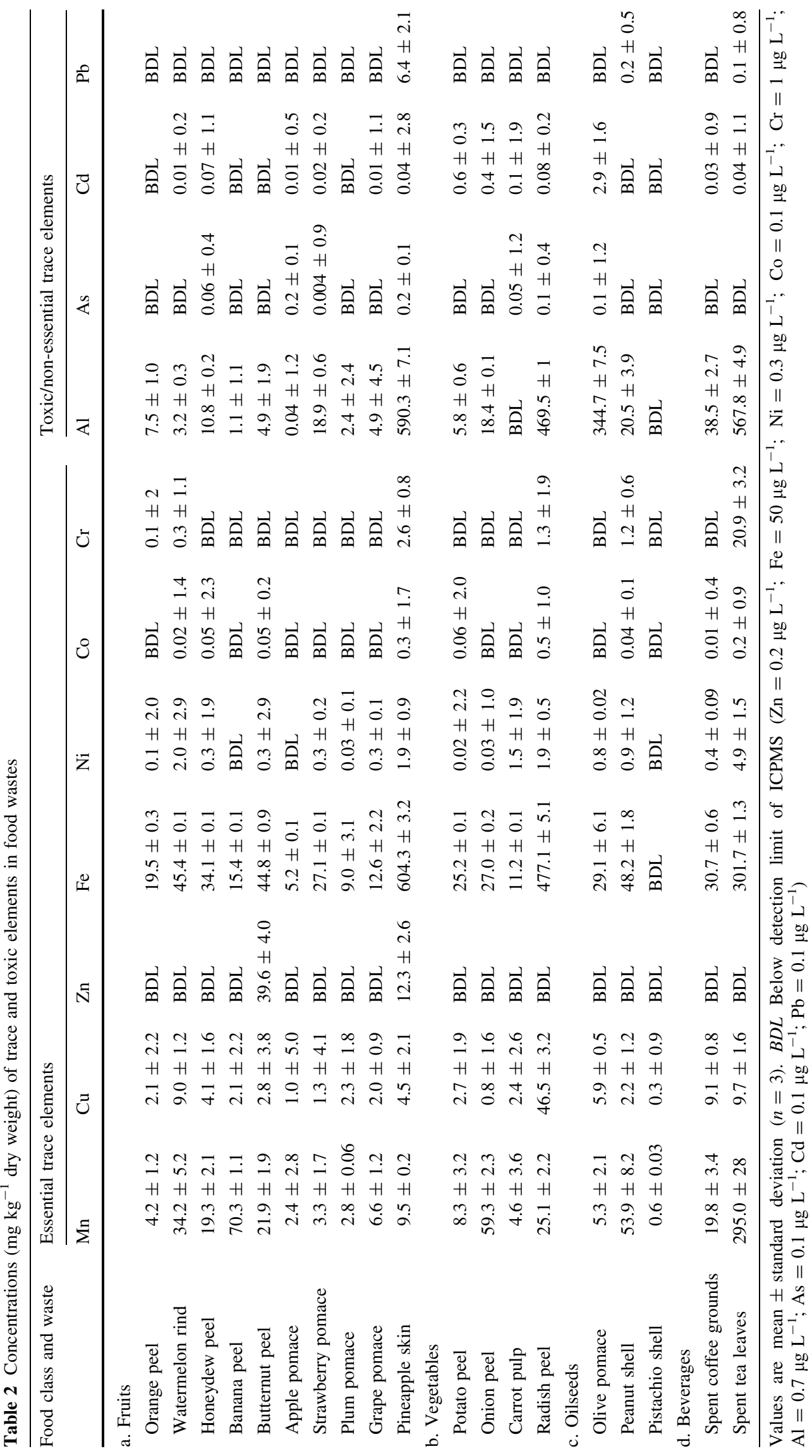


Fig. 2 Concentration of total trace (a) and toxic (b) elements (dry weight basis) in different food wastes
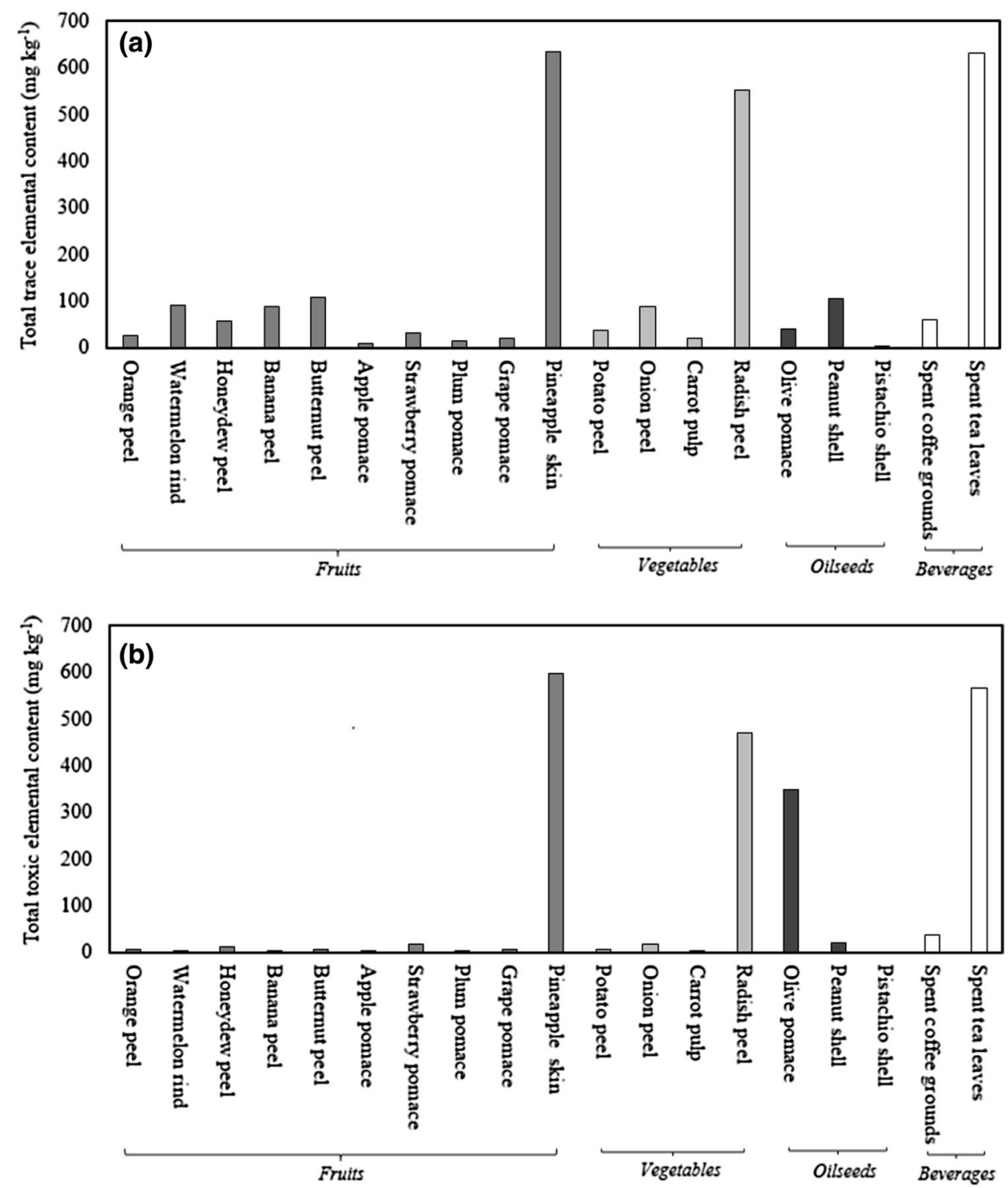

concentrations, only becomes available to plants when the soil $\mathrm{pH}$ falls below 5.5. This would be unusual as the soil most suited for crop production is managed to be a circumneutral pH (Silva 2012). The food wastes screened in this study could, therefore, be used as amendments to upgrade soil fertility and crop productivity (Pellejero et al. 2017; Fidelis and Rao 2017). Apart from the agro sectors, food wastes can even be used in the environmental remediation sector as bioadsorbents of toxic pollutants (Kuppusamy et al. 2015, 2016a, b, 2017).

\section{Conclusion}

Our study confirms that food wastes are rich sources of essential nutrients and the need of the hour is to harness the potential of these natural resources in real industrial systems. Hopefully, the result of this study will help other researchers to further understand the essential macronutrient composition of commonly available food wastes, especially those newly reported. This study should form a basis to selectively identify the most appropriate nutrientrich, less toxic food wastes. Furthermore, research is recommended for the food wastes that are confirmed to be the best nutritive sources to extend their exploitation in the agro-food and pharmaceutical sectors and so avoid treating them as landfill wastes. Such studies should identify the cumulative effects of individual or mixtures of food wastes on soil and plant health when used as soil amendments as well as in the remediation of soil toxicities. Future work could also focus on the extraction of novel nutrient-rich bioactive compounds from the food wastes suitable for human consumption. 
Acknowledgements The authors acknowledge the Australian government in association with Cooperative Research Centre for Contamination Assessment and Remediation of the Environment (CRC CARE) for the International Postgraduate Research Scholarship and CRC CARE top-up fellowship.

Open Access This article is distributed under the terms of the Creative Commons Attribution 4.0 International License (http://crea tivecommons.org/licenses/by/4.0/), which permits unrestricted use, distribution, and reproduction in any medium, provided you give appropriate credit to the original author(s) and the source, provide a link to the Creative Commons license, and indicate if changes were made.

\section{References}

Caetano NS, Silva VF, Mata TM (2012) Valorization of coffee grounds for biodiesel production. Chem Eng Trans 26:267-272. https://doi.org/10.3303/CET1226045

Das K, Smith MC, Gattie DK, Hale Boothe DD (2002) Stability and quality of municipal solid waste compost from a landfill aerobic bioreduction process. Adv Environ Res 6:401-409. https://doi. org/10.1016/S1093-0191(01)00066-1

Er F, Ozcan MM (2010) Chemical compositional properties and mineral contents of some apple cultivars. South-west J Hortic Biol Environ 1:121-131

FAO (2013) FAO statistical yearbook 2009: agricultural production, Food and Agricultural Organization (FAO) of the United Nations, Rome. http://www.fao.org/economic/ess/publicationsstudies/statistical-yearbook/fao-statistical-yearbook/fao-statisti cal-yearbook-2009/b-agricultural-production/en/. Accessed 11 Dec 2015

Fidelis C, Rao BR (2017) Enriched cocoa pod composts and their fertilizing effects on hybrid cocoa seedlings. Int J Recycl Org Waste Agric 6:99-106. https://doi.org/10.1007/s40093-017-0156-8

Gustavsson J, Cederberg C, Sonesson U, van Otterdijk R, Meybeck A (2011) Global food losses and food waste: Extent, cause and prevention, Food and Agricultural Organization (FAO) of the United Nations, Rome. http://www.fao.org/docrep/014/mb060e/ mb060e00.htm. Accessed 14 Oct 2015

Joshi VK, Attri D (2006) Solid state fermentation of apple pomace for the production of value added products. Nat Prod Radiance 5:289-296
Kuppusamy S, Thavamani P, Megharaj M, Naidu R (2015) Bioremediation potential of natural polyphenol rich green wastes: a review of current research and recommendations for future directions. Environ Technol Innov 4:17-28. https://doi.org/10. 1016/j.eti.2015.04.001

Kuppusamy S, Palanisami T, Megharaj M, Venkateswarlu K, Naidu R (2016a) In-situ remediation approaches for the management of contaminated sites: a comprehensive overview. Rev Environ Contam Toxicol 236:1-115. https://doi.org/10.1007/978-3-31920013-2_1

Kuppusamy S, Thavamani P, Megharaj M, Venkateswarlu K, Lee YB, Naidu R (2016b) Potential of Melaleuca diosmifolia leaf as a low-cost adsorbent for hexavalent chromium removal from contaminated water bodies. Process Safe Environ Protect 100:173-182. https://doi.org/10.1016/j.psep.2016.01.009

Kuppusamy S, Venkateswarlu K, Thavamani P, Lee YB, Naidu R, Megharaj M (2017) Quercus robur acorn peel as a novel coagulating adsorbent for cationic dye removal from aquatic ecosystems. Ecol Eng 101:3-8. https://doi.org/10.1016/j.eco leng.2017.01.014

Mussatto SI, Carneiro LM, Silva JP, Roberto IC, Teixeira JA (2011) A study on chemical constituents and sugars extraction from spent coffee grounds. Carbohyd Polym 83:368-374. https://doi. org/10.1016/j.carbpol.2010.07.063

NEPM (2011) Guideline on investigation levels for soil and groundwater, National Environment Protection Council (NEPM), Australia. http://www.scew.gov.au/archive/site-contamination/pubs/ asc-nepm/schedule_b1_guideline_on_investigation_levels_for_ soil_and_groundwater_sep10.pdf. Accessed 26 Dec 2015

Pellejero G, Miglierina A, Aschkar G, Turcato M, Jiménez-Ballesta R (2017) Effects of the onion residue compost as an organic fertilizer in a vegetable culture in the lower valley of the Rio Negro. Int J Recycl Org Waste Agric 6:159-166. https://doi.org/ 10.1007/s40093-017-0164-8

Silva S (2012) Aluminium toxicity targets in plants. J Bot 1-8. doi:10. $1155 / 2012 / 219462$

WHO (2015) Health impacts of chemicals, World Health Organization (WHO), Geneva, Switzerland. http://www.who.int/ipcs/ assessment/en/. Accessed 15 Dec 2015

\section{Publisher's Note}

Springer Nature remains neutral with regard to jurisdictional claims in published maps and institutional affiliations. 